\title{
NOTAS SOBRE POLÍTICA Y SUBSIDIARIEDAD \\ EN EL PENSAMIENTO DE JAIME GUZMÁN
}

Notes about Politics and Subsidiarity in Jaime Guzmán's Thought

\author{
DANIEL MANSUY \\ Universidad de los Andes (Santiago de Chile)
}

\begin{abstract}
RESUMEN
El presente artículo busca mostrar la relación que existe entre política, economía y subsidiariedad en el pensamiento de Jaime Guzmán. En un primer momento se intenta mostrar que las ideas de Guzmán deben ser leídas en función del contexto político y de su anticomunismo. Luego se explica que la subsidiariedad propugnada por Guzmán, piedra angular del nuevo régimen instaurado durante la dictadura militar, tiene un marcado carácter individualista. Esto le permite establecer una alianza con los economistas formados en Chicago sin abandonar nunca su conservadurismo. Finalmente, se muestra qué tipo de tensiones conlleva una síntesis como la propuesta por Guzmán.
\end{abstract}

Palabras clave: Jaime Guzmán, subsidiariedad, economía, Chile, pensamiento político.

\begin{abstract}
The present article explores the relationship between politics, economics, and subsidiarity in the thought of Jaime Guzmán. First, I emphasize the need for a reading of Guzmán's ideas in their political context, and specifically in light of his anti-communism. Second, I analyze his understanding of subsidiarity, a central aspect of the new regime established during the military dictatorship, which I read as a particularly individualistic version of the concept. This made it possible for Guzmán to collaborate with the economists from Chicago without abandoning his own conservatism. Finally, I address some of the tensions that arise from the peculiar synthesis built by Guzmán.
\end{abstract}

Key words: Jaime Guzmán, subsidiarity, economy, Chile, political thought. 


\section{JAIME GUZMÁN Y EL RÉGIMEN CHILENO}

Puede decirse que toda crisis de legitimidad se caracteriza por cuestionar aquellos principios que inspiran un determinado orden. En ese sentido, la pregunta por la legitimidad de las instituciones conduce naturalmente la mirada hacia el momento fundador: indagar acerca del sentido de un determinado orden político implica examinar el pasado que lo vio nacer. No es extraño entonces que en Chile la figura de Jaime Guzmán concite una atención creciente, pues es considerado como uno de los principales ideólogos de la dictadura militar. Ahora bien, muchas veces el debate público se queda en una discusión un poco estéril y binaria: mientras unos miran su figura de modo completamente acrítico, otros ven en Guzmán algo así como la encarnación del mal. Sin embargo, es posible que una auténtica comprensión de la influencia de Guzmán requiera un esfuerzo por superar esa dicotomía que busca emitir un juicio político-moral indiscutido.

En términos muy esquemáticos, el régimen pensado por Jaime Guzmán e implementado durante el gobierno autoritario, consiste en la combinación de democracia protegida con un sistema económico marcadamente liberal, y es justamente la evolución que ha seguido Chile a partir de ese programa que está cuestionada. Por un lado, somos cada día más sensibles a ciertos efectos negativos de la libertad económica (por ejemplo, desigualdad); y, por otro, pareciéramos ser cada día más escépticos respecto de la noción misma de democracia protegida y de los mecanismos contramayoritarios que la acompañan: ¿por qué habríamos de proteger a la democracia de los ciudadanos? (Atria, 2013). Desde luego, no puede afirmarse que este tipo de problemas no hayan existido en el Chile pre-73, que estaba lejos de ser un modelo de integración social y democrática. No obstante, como anotaba Tocqueville (2003: 1009), el progreso conlleva sus propios problemas implícitos, que no pueden obviarse en nombre del mismo progreso sin caer en un razonamiento circular.

Con todo, una consideración adecuada del régimen chileno exige tomar en cuenta algunas cuestiones previas. Por de pronto, no puede olvidarse que todo régimen es una respuesta a un determinado tipo de preguntas, y solo la consideración detenida de esas preguntas nos podrá permitir comprenderlo de modo correcto. En ese sentido, la referencia a Jaime Guzmán es de nuevo ineludible: él encarna de modo eminente el carácter indisoluble de las preguntas y respuestas que dan origen a la política del gobierno de Pinochet. En efecto, Guzmán cristaliza tensiones intelectuales que dieron forma al programa políticoeconómico de la dictadura militar. El fundador del gremialismo fue un verdadero arquitecto en las sombras, que ganó la confianza de Pinochet, puso a sus hombres en lugares clave, y estuvo presente en todas las grandes discusiones y definiciones institucionales de los años 70 (Moncada, 2006: 75). La afirmación de Renato Cristi, de que Guzmán fue un auténtico hombre de Estado que ofreció a los militares una articulación política basada en un proyecto de largo plazo, contiene mucho de verdad (Cristi, 2011: 47; Barros, 2005: 120). En concreto, su alianza con los economistas liberales formados en Chicago fue decisiva para darle un sustento político al programa económico (Boetsch, 1998: 82). Recordemos que los militares carecían de proyecto definido, y que en América Latina 
los uniformados solían adoptar programas populistas. ${ }^{1}$ Hay aquí un hecho político de la mayor importancia, especialmente si consideramos que Guzmán había adscrito a posiciones antiliberales en su juventud.

La paradoja puede formularse del modo siguiente. Guzmán fue un católico ferviente, que nunca ocultó su inclinación por la vida sacerdotal, y que se refería con frecuencia a cuestiones espirituales en sus intervenciones públicas. Sin perjuicio de lo anterior, durante los años 70 Guzmán brinda un decidido apoyo al programa económico liberal, convirtiéndose de hecho en el aval de ese proyecto a ojos de la derecha más tradicional y conservadora. Para lograrlo, Guzmán elabora una síntesis política, que se asume capaz de conciliar las enseñanzas sociales del catolicismo con un liberalismo económico bastante acentuado (Moncada, 2006: 19). Las líneas que siguen intentan dar cuenta de esa síntesis, a partir de sus textos publicados y de sus aportes al interior de la Comisión Ortúzar.

Con todo, la tarea no está exenta de dificultades. Por de pronto, conocemos poco de la figura de Jaime Guzmán. No están editadas sus obras completas -ni parece haber proyecto para hacerlo- ${ }^{2}$ ni hay disponible una biografía rigurosa que dé cuenta de su vida. ${ }^{3}$ Por otro lado, y aunque la cuestión es controvertida, Guzmán parece haber sido más un político que un intelectual. ${ }^{4} \mathrm{Su}$ inteligencia estuvo siempre dirigida a la resolución de problemas prácticos, lo que exige considerar al actor político a la hora de analizar su pensamiento. No parece haber en Guzmán una filosofía política abstraída de su contexto. Esto no le impide tener principios -como veremos, hay ideas que lo acompañan durante toda su trayectoria-, pero los va aplicando a lo largo de su vida en función de las circunstancias. Además, escribió pocos textos más elaborados que discursos y columnas de opinión. Es innegable que los problemas intelectuales no le son indiferentes, y Guzmán está lejos de ser el arquetipo del político desinteresado por el mundo de las ideas. El líder gremialista encarna de algún modo un tipo, el del políticointelectual, como pueden haberlo sido Eduardo Frei u Orlando Millas; pero es en función de los escenarios políticos movedizos que Guzmán va fijando su propia doctrina. Todo esto exige un esfuerzo especial por distinguir los argumentos puramente tácticos de las intuiciones que permanecen durante toda su trayectoria. ${ }^{5}$

1 Por lo mismo, contrariamente a lo afirmado por Manuel Antonio Garretón, las decisiones económicas de los militares no tenían nada de evidente (1998: 40). Sobre esto, ver Valdivia (2003) y Gárate (2012: 181-195).

Una semana después del asesinato de Jaime Guzmán, Gonzalo Rojas -uno de sus discípulos destacadosescribió una columna donde llamaba a una tarea urgente: la edición de su obra completa y la elaboración de una biografía. 23 años después, ninguno de estos proyectos ha visto la luz (Rojas, 1991).

3 El texto reciente de Cristián Gazmuri (2013) no es más que una recopilación de anécdotas y especulaciones que no logra dar cuenta de la complejidad del personaje.

4 Renato Cristi defiende la tesis de que el pensamiento de Guzmán es coherente y puede ser sistematizado. Belén Moncada, Arturo Fontaine y Carlos Huneeus, por su parte, creen que Guzmán fue más político que intelectual y que, en consecuencia, la contingencia es fundamental (y determinante) para comprender sus ideas (ver Cristi, 2011: 17; Moncada, 2006: 30 y 250; Fontaine en Guzmán, 1991a: 251; Huneeus, 2000: 335).

5 Cristián Gazmuri afirma que no es posible estudiar en profundidad la vida y obra de Guzmán, y sugiere que basta la tradición oral para conocerlo (2013: 9). Según Gazmuri, su pensamiento era "banal" (2013: 97). Sin embargo, es difícil que un pensamiento puramente "banal" haya tenido la influencia que Gazmuri le reconoce (2013: 11). 


\section{EN EL ORIGEN, UNA NEGACIÓN}

En el libro de recuerdos que escribió relativos a su hermano, Rosario Guzmán afirma que hay una idea que este no abandonó nunca: el antimarxismo (Guzmán, Rosario, 1991: 115). En efecto, toda la trayectoria de Jaime Guzmán puede ser leída desde esta óptica: Guzmán fue, ante todo, profundamente anticomunista y antimarxista (Moncada, 2006: 30). Esta dimensión de su pensamiento es constante y sostenida en el tiempo, y lo acompaña, literalmente, hasta el final de sus días (ver su último discurso en el Congreso pleno del 23 de marzo de 1991, Guzmán, 1991a: 567-570). En este sentido, fue un hombre de su tiempo -de la Guerra Fría-, que eligió su bando a muy temprana edad. Jaime Guzmán pensó siempre la política dentro de un cuadro determinado, donde el enemigo tenía una encarnación práctica en la amenaza soviético-comunista.

Esta negación, desde luego, tiene ciertas implicancias. Por de pronto, lo conduce a descartar constantemente, y desde muy temprano, cualquier búsqueda de una eventual tercera vía entre capitalismo y socialismo. Incluso en sus textos de juventud, donde hay una crítica abierta al liberalismo filosófico (Guzmán, 1991a: 256; el texto original de 1969), el fundador del gremialismo aparta cualquier posibilidad de camino intermedio. Recordemos que la búsqueda de una tercera vía involucraba en ese entonces a amplios sectores ligados al catolicismo. Sin embargo, para él, desde mediados de los 60, la única actitud legítima en una lógica de Guerra Fría es el rechazo radical del marxismo. En ese contexto, no es de extrañar que el proyecto democratacristiano siempre le haya parecido altamente sospechoso. Guzmán no podía sino rechazar esa propuesta, cuyo propósito explícito consistía en buscar una alternativa a los modelos capitalista y comunista. Así, considera que la posición democratacristiana concede cuestiones fundamentales al diagnóstico marxista, y que eso la condena a inclinarse sistemáticamente hacia la izquierda (Fermandois, 2013). A la larga, esa tendencia favorece la dinámica marxista, que se vuelve plausible (Guzmán, 1991a: 377). La única estrategia efectiva frente a una izquierda cada vez más agresiva consiste, a su juicio, en una oposición frontal, que permita defender ciertos bienes fundamentales. La vida y la acción de Guzmán se explican a partir de estos esfuerzos.

Para fundamentar su rechazo a cualquier forma de socialismo, Guzmán recurre, desde 1965, a una idea presente en el pensamiento católico: la prioridad del hombre respecto de la sociedad, la que, según él, es tanto ontológica como teleológica. Ontológica porque el hombre sería anterior a la sociedad: Guzmán afirma que es posible concebir un hombre sin sociedad, pero no una sociedad sin hombres. Prioridad teleológica, en seguida, porque la sociedad está hecha para el hombre, y el fin último de la persona humana la trasciende. ${ }^{6}$ Es tal la fuerza con la que Guzmán afirma esta prioridad que no teme entrar

6 Ver Guzmán (1965), donde se afirma que el hombre tiene "prioridad ontológica y de finalidad sobre la sociedad y el Estado", ya que "es un ser substancial con un destino eterno, mientras que el Estado es un ser relacional". Guzmán concluye así: "puede haber hombres sin Estados, pero no puede haber Estados sin hombres" (p. 4). En este texto, Guzmán parece utilizar como sinónimos "Estado" y "sociedad". De hecho, en la Declaración de principios de la Junta de gobierno (redactada por Guzmán) se formula la misma idea, y se utiliza solo la palabra "sociedad". Ver también Guzmán (1992: 46) ("la sociedad constituye solo un ser accidental de relación”); 
en una pendiente delicada, en especial considerando la antropología que dice suscribir: su argumentación asume premisas individualistas cercanas al contractualismo. Este se caracteriza precisamente por pensar la posibilidad sugerida por Guzmán: el hombre fuera de la sociedad. En este sentido, Renato Cristi apunta que la argumentación de Guzmán supone que la sociedad es un accidente contingente en lugar de uno necesario, que sería lo propio de la tradición tomista (Cristi, 2011: 88; Moncada, 2006: 37-38 y 2012: 225-226). Desde luego, puede tratarse solo de una cuestión de acentos, pero parece difícil negar la conexión existente entre este énfasis de Guzmán y la idea, sugerida por él posteriormente, de que la sociedad tiene un carácter instrumental respecto de los bienes individuales. ${ }^{7}$ Desde una perspectiva aristotélica, es significativo notar que la sociedad es una condición necesaria del bien humano. Dicho de otro modo, la (necesaria) afirmación de la primacía de la persona no implica olvidar el principio de totalidad. De hecho, el propio Tomás de Aquino utiliza la metáfora orgánica para dar cuenta de la sociedad: ninguna parte se entiende sin el todo (Tomás de Aquino, 1995, I, 1 y 2002, II-II, q. 58, a. 5). Lo paradójico de todo esto es que este tipo de afirmaciones acercan a Guzmán a la corriente personalista que se encuentra en el fundamento doctrinario de la Democracia Cristiana. En efecto, y como bien lo ha notado Charles de Koninck, los personalistas tienen dificultades para integrar el principio de totalidad en su sistema (Delsol, 2013: 36-37 y De Koninck, 1943). Algo parecido le ocurre a Jaime Guzmán, que no quiere conceder nada que pueda parecer cercano a las tesis marxistas. Nos parece que su individualismo teórico debe ser leído en esa perspectiva: Guzmán se acerca a premisas individualistas pues ellas le dan mayor consistencia a su crítica del comunismo. Para lograr su objetivo, no duda en utilizar nociones presentes en la Doctrina social de la Iglesia, pero que están allí de modo moderado y equilibrado con otros principios. Guzmán toma lo que le sirve, y tiende a omitir aquello que no es funcional a sus objetivos. ${ }^{8}$

Es también importante destacar que, al momento de formular por primera vez estas tesis (1965), Jaime Guzmán no conocía aún la doctrina económica liberal. Su contacto con ella se producirá más tarde, en la conformación del movimiento gremial y durante el gobierno de Allende (Arancibia y Balart, 2007: 156 y Gárate, 2012: 144-154). Sin embargo, su comprensión de la sociedad está marcada por un anticomunismo radical que lo acerca a posiciones individualistas. En ese sentido, su pensamiento tiene hilos de continuidad que permiten explicar incluso las rupturas o quiebres aparentes: Guzmán estaba bien preparado para acoger las doctrinas más liberales, pues su anticomunismo

1991: 256, y las sesiones n. 40, 14 de mayo de 1974, y n. 127, 5 de junio de 1975 de la Comisión Ortúzar (en esta última: "Toda asociación constituye una persona moral, un ser accidental, evidentemente, de relación"). Sobre esto, ver la reveladora discusión que sostuvieron Mario Góngora y Arturo Fontaine a partir del Ensayo histórico del primero (Góngora, 1986: 313-330).

8 En cualquier caso, es interesante notar que Fiducia -grupo en el que participó Guzmán-combinaba un férreo tradicionalismo con una defensa a ultranza del derecho de propiedad, considerado como sagrado (Correa, 2005: 119). Sobre esto, ver González Navarro (2012). En ese sentido, no hay que menospreciar la influencia de Plinio Correa en Jaime Guzmán, aunque este terminara abandonando el tradicionalismo. Plinio opone constante y radicalmente comunismo y catolicismo (Correa, 1975), y considera que debe evitarse "la influencia socialista en las leyes, porque el socialismo prepara eficazmente para el comunismo" (Correa, 1964). Ambas ideas están en el centro de la elaboración político-intelectual de Jaime Guzmán. 
buscaba una respuesta contundente al discurso estatista. El liberalismo económico le brinda luego una preciosa ayuda en esa empresa.

\section{SUBSIDIARIEDAD, POLIITICA Y DEMOCRACIA PROTEGIDA}

Como puede verse, la posición de Guzmán frente a la izquierda es bastante defensiva. Con todo, sería un error creer que su figura se agota en esta negación. La originalidad de Guzmán reside precisamente en su capacidad de elaborar, a partir de ese rechazo, un diagnóstico y un programa capaces de constituirse en motivos políticos generadores de dinámica colectiva. Dicho de otro modo, Guzmán supo transformar el rechazo en plan de acción. Con el paso del tiempo, este rasgo le daría una fuerza inigualada al interior de la derecha chilena, una de cuyas características arquetípicas es defender posturas puramente reactivas, asumiendo de modo acrítico el diagnóstico contrario (Correa, 2004).

Por lo mismo, y aunque el anticomunismo es crucial para dar cuenta de la trayectoria de Guzmán, resulta insuficiente para inspirar una auténtica acción programática. Guzmán entendía esto mejor que nadie (y, en parte, eso lo alejaría del mundo tradicionalista). Así, para dar forma a un nuevo orden social, el fundador del gremialismo recurre desde muy temprano a un concepto tomado directamente de las enseñanzas sociales de la Iglesia: el principio de subsidiariedad. Este principio, cuyos orígenes pueden rastrearse en los textos de Aristóteles y Altusio, y que fuera desarrollado por primera vez de modo explícito por Ketteler, está expuesto en dos encíclicas, Quadragesimo anno (1931) y Mater et magistra (1961). ${ }^{9}$ En términos muy simples, el principio de subsidiariedad indica que la competencia de una acción o tarea social debe ser atribuida a la agrupación o entidad que mejor pueda cumplir dicha tarea, que suele ser aquella más cercana al tipo de acción requerido. La finalidad del principio es preservar la vitalidad propia de la sociedad civil, pues supone que el despliegue de lo humano, en función de la naturaleza social del hombre, necesita de múltiples asociaciones indispensables para su desarrollo. Todo esto implica que las sociedades mayores no deben sustituirse sin razón a las sociedades menores, pero también que las sociedades mayores tienen el deber de actuar si las sociedades menores no cumplen por sí solas con sus propios fines -lo que no es necesariamente excepcional-, ayudándolas a cumplir con esos fines o, eventualmente, supliéndolas en su cumplimiento. Los pontífices utilizan este concepto para criticar la tendencia estatista del socialismo: el Estado no tiene vocación a hacerlo todo, pues ese afán puede ahogar la vitalidad propia de la sociedad civil. Pero el principio también afirma que hay acciones que no pueden ser asumidas sino por sociedades mayores, debido a su complejidad, o porque guardan directa relación con el bien del todo. El rechazo al socialismo no equivale a una adhesión plena al liberalismo, y el interés del principio reside precisamente en la distancia que toma respecto de ambas alternativas. 
En cualquier caso, no puede fijarse en abstracto una cantidad exacta de participación estatal o privada: el principio exige una reflexión situada antes de ser aplicado. ${ }^{10}$

Esto nos conduce a la pregunta siguiente: ¿quién determina la atribución de la competencia de cada entidad o asociación? No parece sensato entregar dicha potestad a la sola espontaneidad de las sociedades intermedias, pues estas son necesariamente parciales. Puede suponerse entonces que, al afirmar el principio, se atribuye, aunque sea de modo implícito, cierta potestad a la sede política, no para sustituir a la sociedad civil, pero sí para apreciar la necesidad y el carácter de las eventuales intervenciones. Dicho de otro modo, el principio de subsidiariedad requiere necesariamente una mediación política: su significado hic et nunc no es inmediato ni evidente. Esta necesidad de mediación política nos conduce directamente a las enseñanzas de Aristóteles. Según el filósofo griego, lo político tiene vocación arquitectónica, pero eso no implica que esté llamada a sustituirse al todo: lo político debe indicar a cada parte cuál es su ubicación al interior del todo (Descombes, 2008: 41). Si esto es plausible, entonces el principio de subsidiariedad no puede comprenderse ni practicarse sin referirse a un orden más general, pues requiere de una articulación político-prudencial. En ese sentido, parece difícil pensar el principio de subsidiariedad como fundamento de un liberalismo económico -o neoliberalismo- muy acentuado. ${ }^{11}$ En efecto, este tiende a prescindir de la dimensión política, y eso explica su acento individualista -no existe algo así como "la sociedad"-. Sin embargo, el principio de subsidiariedad solo tiene sentido al interior de una comprensión propiamente política de los fenómenos humanos. Por cierto, es innegable que el principio busca proteger la vitalidad propia de la sociedad civil, y en ese sentido puede ser convergente con cierto liberalismo económico; pero ya que el objetivo es precisamente resguardar dicha vitalidad, no puede olvidarse que las amenazas a ella pueden venir tanto del Estado como de la misma sociedad civil: esta posee muchos niveles de acción que pueden entrar en conflicto.

En cualquier caso, Guzmán hace suyo este principio anclado en la tradición, y sugiere una lectura singular. En efecto, como veremos, propone una interpretación liberal del principio, que tiende a reducirlo a una cuestión binaria de intervención o abstención del Estado, obviando que se trata -en primer término- de una cuestión de competencias que involucra a todos los estamentos sociales, y que está lejos de agotarse en la dialéctica Estado-mercado. Por lo mismo, Guzmán tiende a sobredimensionar el aspecto negativo de no intervención, minimizando el aspecto positivo. Esto le permite afirmar la libertad de movimiento de los cuerpos intermedios y, a la larga, de los individuos. ${ }^{12}$ De hecho, hace escasa mención del contexto general que explica la subsidiariedad en el seno de la enseñanza católica: función social de la propiedad, rechazo del liberalismo económico

Guzmán reconoce esto en algunas de sus intervenciones en la Comisión Ortúzar (ver, por ejemplo, la discusión sobre educación en la sesión n. 141, 24 de julio de 1975). Para un panorama general de las discusiones actuales sobre subsidiariedad, ver Evans y Zimmermann (2014).

11 Por razones de espacio no podemos tratar aquí la extensa discusión en torno al concepto de "neoliberalismo", por lo que remitimos a Audier (2012) y Ghersi (2004).

12 Desde luego, Guzmán se refiere en ocasiones al aspecto positivo de la subsidiariedad, aunque no ofrece una elaboración que permita comprender cómo calza con la orientación más general de su discurso. Desde luego, estas tensiones deben ser leídas a la luz del carácter contingente de su propuesta. 
extremo, conciencia de los riesgos del capitalismo. Nada de esto es casual: a ojos de Guzmán, el principio de subsidiariedad permite oponerse con vigor a cualquier proyecto de hegemonía estatal. En ese sentido, la subsidiariedad tiene mucho de herramienta útil en la lucha contra el marxismo, y por eso Guzmán no teme distorsionarla si es necesario: a fin de cuentas, toda herramienta debe adaptarse a los fines que persigue. Al mismo tiempo, su interpretación de la subsidiariedad le permite converger, con mínimas diferencias prácticas, con los economistas formados en Chicago. En el fondo, la subsidiariedad le permite a Guzmán fundamentar una economía convergente con la propuesta liberal desde la Doctrina Social de la Iglesia: es su propio punto de Arquímedes.

Es posible identificar esta tendencia desde los escritos tempranos de Guzmán, aunque con algunas ambigüedades. En un texto de 1969, por ejemplo, vincula la subsidiariedad con el principio orgánico, ${ }^{13}$ al tiempo que la lee desde una óptica individualista. En el mismo escrito, Guzmán deriva el derecho a la propiedad privada y a la libre iniciativa en el campo económico del principio de subsidiariedad. Según él, esta es, más que una fórmula eficaz, la fiel expresión de "la naturaleza humana y salvaguardia de su propia libertad" (Guzmán, 1991a: 256). Guzmán justifica aquí el principio de subsidiariedad retomando el argumento de la prioridad de la persona. Es importante comprender esta vinculación, pues Guzmán la utilizará para justificar sus posiciones en la Comisión Ortúzar. El fundador del gremialismo afirma en 1969 que las agrupaciones humanas "solo tienen por campo específico de acción aquel que el hombre no puede desarrollar por sí solo" (Guzmán, 1991a: 256). Ese sería el fundamento de la subsidiariedad (y de la sociabilidad): suplir al individuo en sus insuficiencias naturales. El pasaje es crucial, porque da cuenta de cuán lejos lleva Guzmán el argumento de la prioridad, y también permite comprender la aplicación práctica de la subsidiariedad: lo social es visto como un remedio a una insuficiencia humana, más que como una elevación. Es llamativo el modo en que lo explica, pues pareciera suponer que el hombre puede hacer algo relevante por sí solo (allí donde las agrupaciones humanas no podrían intervenir): en ese contexto, incluso la familia parece adquirir un carácter supletorio. Sin embargo, si acaso es cierto que el hombre es un animal político, entonces todas sus capacidades propiamente humanas están vinculadas a su carácter social. Así, el criterio de Guzmán para definir el campo específico de la sociedad parece insuficiente.

En ese sentido, la defensa guzmaniana del principio de subsidiariedad contiene una premisa controvertida, y en tensión con otras dimensiones de su pensamiento. Por de pronto, como dijimos, su propuesta se acerca al contractualismo en cuanto sugiere que la sociedad tiene un carácter instrumental: los fines están siempre concebidos desde el individuo. Por lo mismo, la esfera de acción social está estrechamente limitada por aquellos fines que solo podemos obtener juntos. Como bien nota Belén Moncada, se echa en falta en la argumentación de Guzmán el principio de solidaridad: los deberes tienden siempre a ir en dirección descendente, y no queda claro cómo podrían articularse bienes comunes en una lógica de ese tipo (Moncada, 2006: 84). Guzmán ofrece así

13 Dice, por ejemplo, en 1969, que "En el respeto y adhesión a estos principios reside la única posibilidad de conformar una sociedad realmente orgánica" (Guzmán, 1991a: 256). 
una visión singular del principio de subsidiariedad, que no puede sino contener una orientación individualista basada en una concepción apolítica del hombre. Esto tiene dos consecuencias relevantes, que veremos luego en la discusión constitucional. Por un lado, la acción pública es siempre vista como un remedio para curar insuficiencias contingentes de los privados. Chantal Delsol explica la subsidiariedad liberal desde Locke, recogiendo una idea expresada en el Segundo discurso: el papel de la persona pública sería análogo al del padre de familia, quien solo debe suplir una insuficiencia temporal por definición (Delsol, 2013: 84-87; Locke, 1997: 74-75 y 173). Naturalmente, el remedio al mal contingente solo puede ser transitorio, y eso explica el carácter momentáneo de la acción pública concebida por Guzmán. Esto nos conduce a la segunda consecuencia: hay un trasfondo progresista, al asumirse que el curso de la Historia resolverá las dificultades que impiden a los privados superar sus incapacidades. Debido a que la insuficiencia es accidental, entonces basta ofrecer lo mínimo, esperando que el tiempo ofrezca la solución óptima (Delsol, 2013: 83-98).

No es de extrañar entonces que incluso las ambivalencias del discurso vayan desapareciendo durante los años 70. El principio de subsidiariedad será comprendido, por Guzmán y los economistas liberales, como libertad individual y económica. De más está decir que, en ese contexto, los gremios -fundamentales en la concepción orgánica- ya no tienen ningún papel relevante. El principio ya no estará pensado como una manera de resguardar el tejido de sociedades intermedias y la vitalidad del orden colectivo, sino como la protección del libre mercado. Ambas cosas no son necesariamente contradictorias, pero en la versión original del principio lo primero contiene a lo segundo: la libertad económica es importante, entre otras cosas, porque garantiza la autonomía debida de las sociedades intermedias que son algo más que agentes económicos. Todo esto implica una cierta despolitización de la sociedad, porque los individuos y los cuerpos intermedios son concebidos como autónomos respecto del todo, que es concebido a su vez como instrumental frente a las necesidades individuales. ${ }^{14}$ En este contexto no queda demasiado lugar para la dimensión arquitectónica de la política. La vida humana se juega cada vez menos en sede política, para dar paso a una creciente dimensión privada, entendida a su vez desde la economía.

La noción misma de democracia protegida está intrínsecamente ligada a esta perspectiva. ${ }^{15}$ Según Guzmán, el principio de subsidiariedad es perfectamente congruente con un régimen presidencial fortalecido, que supone el debilitamiento de la sede parlamentaria (Guzmán, 1991a: 337, 376 y 408; textos de 1979 y 1980). La democracia debe ser protegida de los riesgos totalitarios, que provienen del exceso de política (Guzmán, 1991a: 377). Es indispensable entonces configurar un cuadro político-social que imposibilite el triunfo de cualquier tipo de extremismo (Actas, sesión n. 45, 13 de junio de 1974), y es solo

14 Guzmán se defiende de esta acusación señalando que el afán despolitizador del gremialismo “no se refiere a las personas, sino a las instituciones no políticas de la sociedad" (Guzmán, 1992: 53). Esto puede entenderse en un contexto donde el marxismo, a ojos de Guzmán, intentaba instrumentalizar los cuerpos intermedios. Con todo, es difícil comprender cómo las sociedades intermedias, en cuanto tales, podrían desentenderse de lo que ocurre en la polis.

15 Cabe señalar que el mismo Guzmán ocupa la noción de democracia protegida (Actas, sesión n. 338). 
mediante esta neutralización de la política que podrá advenir una auténtica democracia de masas. Para consolidarse, esta nueva democracia requiere una economía de mercado que dificulte las rupturas violentas, y eso exige "arraigar en los chilenos el ejercicio de las libertades económico-sociales". Así, Guzmán dice en 1982 que

el ejercicio por varios años de aquellos espacios de creciente libertad que el actual gobierno ha generado en el ámbito educacional, de la salud, de la libertad de trabajo y de sindicación, de la previsión social y, en general, de todas las actividades económicas o empresariales, resulta imprescindible para que ellas se hagan carne en todos los chilenos, de modo que resulte muy difícil revertirnos hacia esquemas estatistas que supongan cercenar libertades que ya se habrán apreciado e incorporado a su vida por cada persona (Guzmán, 1991a: 438).

No es seguro que el tiempo le haya dado razón al optimismo de Guzmán. Este asume que las libertades económicas pueden ser suficientes para dotar de sentido un orden político. No deja de ser paradójico que esta afirmación comparta, en alguna medida, una ilusión típicamente marxista, donde el cambio en las condiciones materiales de vida altera automáticamente las superestructuras sociales, y que esas alteraciones pueden ser previstas con cierta precisión. ${ }^{16}$ En esa lógica, Guzmán también desvaloriza el sufragio como instancia de participación, atribuyéndole importancia a otro tipo de decisiones, como las de consumo, que serían manifestaciones básicas de participación social ${ }^{17}$ (Moncada, 2006: 208). Guzmán reduce al extremo el campo de lo político, subordinándolo a la acción privada: como el hombre es anterior y prioritario respecto de la sociedad, entonces la legitimidad del Estado solo puede residir en los servicios que presta a los intereses individuales. Por lo mismo, las decisiones individuales (incluyendo las de consumo) no son menos relevantes que las decisiones propiamente políticas -cuyo campo debe estrecharse-. En el mundo de Guzmán, las decisiones privadas configuran la sociedad, una vez que la política ha sido relegada a su mínima expresión. ${ }^{18}$ La democracia protegida da forma a una sociedad donde los individuos ejercen su libertad en el campo privado: ese es, en el fondo, el antídoto pensado por Guzmán frente a un Estado opresor de las libertades individuales. ${ }^{19}$

Esta ilusión bien puede encontrar su origen en Michael Novak. No insistimos aquí en la influencia de Novak sobre Guzmán, porque nos parece que el pensamiento de Guzmán ya está formulado en sus líneas fundamentales cuando conoce a Novak a principios de los 80 . Este refuerza sus intuiciones y le ofrece argumentaciones interesantes, pero no modifica su pensamiento en lo sustantivo (Novak, 1984).

17 "Hay otro modo aún más básico de participar socialmente, pero que no suele valorarse como tal. Me refiero a la participación individual o familiar. A las múltiples decisiones que cada persona adopta diariamente respecto de su propio destino personal y familiar" (Guzmán, 1981; Moncada, 2006: 208).

18 En ese contexto, no es extraño que Guzmán haya sido partidario del voto voluntario (Actas, sesión n. 73, 26 de septiembre de 1974).

19 En esta materia, Guzmán va bastante lejos. Propone un sistema bicameral, con un Senado mixto -integrado por senadores elegidos y designados-, que tendría un poder de veto para la formación de la ley, que solo podría ser vencido por dos tercios de la Cámara baja (Actas, sesión n. 349, 12 de abril de 1978). Al mismo tiempo, pretende limitar notablemente las candidaturas presidenciales, exigiendo el patrocinio de doce senadores: así, dice se lograría en la generación de candidaturas un "tamiz de raigambre democrática" (Actas, sesión n. 399, 12 de julio de 1978 y n. 404, 18 de julio de 1978). El bicameralismo de Guzmán se explica porque no quiere abandonar su idea de composición mixta del Parlamento, pero piensa que eso sería muy complejo de realizar en un sistema unicameral (Actas, sesión n. 323, 26 de octubre de 1977). 
La orientación liberal de estos planteamientos también se refleja en la defensa que Guzmán hace, por momentos, del modelo económico como un programa coherente y no negociable. En 1981, por ejemplo, afirma que "no habrá concesión alguna a intereses sectoriales a costa de la congruencia global del modelo" (Guzmán, 1991b: 107). Para él, la estrategia del gobierno es "un todo coherente, no sujeto a remiendos irresponsables o interesados que solo terminaría por destruirla" (Guzmán, 1991b: 108). Guzmán utiliza aquí una retórica muy cercana a la de los autores del Ladrillo, que siempre se negaron a aplicar sus políticas de manera parcelada, ya que estas constituían un todo integral que no podía ser dividido sin afectar la unidad del conjunto. ${ }^{20}$ Este punto de vista es perfectamente válido, pero tiende a alejarse de las exigencias propias de la actividad política, que consiste en buscar acuerdos entre visiones divergentes, y en permitir dosis de flexibilidad sin renunciar a la vocación arquitectónica (Aron, 1997: 50-53). Al asumir el discurso liberal más ortodoxo respecto de la "coherencia" del programa, Guzmán deja poco lugar para los matices al interior de lo que él mismo llama "modelo". ${ }^{21}$

\section{SUBSIDIARIEDAD Y NUEVA CONSTITUCIÓN}

Jaime Guzmán tuvo oportunidad de plasmar muchas de estas ideas al interior de la Comisión de Estudios para la Nueva Constitución, que integró desde septiembre de 1973. El líder del gremialismo tuvo allí un papel destacado, e intervino en casi todos los temas de manera preparada. Fue también un actor muy hábil, que supo ceder en lo accidental para persuadir en lo que considera fundamental. En palabras de Gonzalo Vial, Guzmán fue "el verdadero constituyente del gobierno", y su voz fue la "más escuchada y consistente" al interior de la comisión (Vial, 2010: 66). Por lo mismo, las Actas constituyen una fuente valiosísima para estudiar su pensamiento.

Allí puede verse, por ejemplo, su abandono de la concepción orgánica de la sociedad, que se hace patente cuando la Comisión invita a exponer a Enrique Pascal, con quien Guzmán se enfrenta (Actas, sesión n. 27, 28 de marzo de 1974). Más tarde, aboga por la liberalización de los colegios profesionales que, según él, tienden a convertirse en auténticas tiranías. ${ }^{22}$ Así, desde los primeros meses de 1974 Guzmán se convierte en el principal adversario de aquellos que esperaban que el régimen militar estableciera un orden corporativo prescindente de los partidos políticos. El dato parece hoy relativamente ladrillo, 1992: 22).

21 Cabe señalar que, tras la crisis de 1982, Guzmán va a moderar notablemente su discurso (ver por ejemplo Guzmán, 1991a: 459-460).

22 Actas, sesión n. 127, 5 de junio de 1975. En este tema, es patente como Jaime Guzmán tuerce la voluntad constituyente inicial. En la primera sesión de la Comisión (24 de septiembre de 1973), Enrique Ortúzar señala que una de las medidas indispensables del nuevo orden constitucional era atribuir "efectiva participación de los gremios, colegios profesionales, mujeres, juventud y Fuerzas Armadas, los cuales unidos y sin odios podrían obtener en forma rápida y eficaz la prosperidad del país y el bienestar de la población". Por cierto, al defender esta liberalización Guzmán abandona definitivamente cualquier tipo de orden corporativo (Cristi, 2011: 186-187); y no puede señalarse, como lo hace Moncada, que en Guzmán el liberalismo se haya complementado con el "gremialismo" (Moncada, 2006: 112): más bien cabría decir que el primero tiende a absorber políticamente al segundo. 
trivial, pero la cuestión estaba lejos de ser pacífica: como explica Gonzalo Rojas, hubo durante toda la década una intensa disputa entre duros y blandos acerca del carácter de la nueva democracia, que enfrentaba a los partidarios de repetir el régimen franquista con los abogados del sistema democrático. Guzmán maniobró con habilidad para ganar progresivamente la confianza de Pinochet, e imponer su punto de vista al interior del régimen (Rojas, 1998: 287-288; sobre su pugna con Manuel Contreras, ver Salazar, 1994: 111-128). Por eso es equívoco afirmar, como lo hace Carlos Huneeus, que Guzmán haya suscrito, hasta fines de los años 70, un modelo franquista: desde 1974, Guzmán abandona cualquier tentación autoritaria, para elaborar lo que llamará más tarde una "democracia protegida", y adquiere un papel preponderante al interior de la comisión Ortúzar (Huneeus, 2000: 334; Vial señala que Guzmán inicia su giro doctrinario hacia 1975, 2002: 373).

La Comisión también fue el lugar de vivas discusiones respecto del carácter específico de la subsidiariedad. Las posiciones de Guzmán eran criticadas con frecuencia por Sergio Diez y Jorge Ovalle, quienes desaprobaban la orientación liberal de sus argumentos. Quizás el caso más paradigmático de estas diferencias se produce cuando la Comisión trata la noción de bien común y los deberes del Estado. El fundador del gremialismo propone establecer que la misión del Estado sea "promover el bien común". Para alcanzarlo, en la propuesta de Guzmán, el bien común "asegura respeto y protección eficaz a los derechos inalienables que arrancan de la naturaleza humana, reconoce la existencia y ampara la formación y el desarrollo de las sociedades intermedias, garantizándoles una adecuada autonomía", y "favorece la participación individual y social" (Actas, sesión n. 45, 13 de junio de 1974). Sergio Diez objeta la propuesta, aduciendo dos motivos. Por un lado, cree que el texto debe contener una alusión explícita al deber del Estado de "propender a una equitativa distribución de la renta nacional" ${ }^{23}$ Es una idea ausente de la proposición original, y que naturalmente introduce un matiz de importancia. Pero Diez agrega una segunda observación, en concordancia con la primera. Desde su perspectiva, la definición de Guzmán "es quizás un poco liberal". El Estado así configurado sería, en sus palabras, un "Estado estático", que se limita a evitar la comisión de abusos, un Estado "que solo asegura respeto y protección". Diez cree que el Estado no solo debe proteger y asegurar fines, sino que debe asumir una postura dinámica, capaz de separarse del "Estado liberal", cuya característica es hacer "caso omiso de los problemas de las sociedades intermedias o de los problemas económicos".

La objeción de Diez toca un punto central: ¿qué papel debe asumir el Estado en la vida social, y en virtud de qué principios? La respuesta de Guzmán es particularmente enérgica, pues comprende que no se trata de un detalle, y que si no controla la discusión en este punto, la Comisión puede tomar luego una dirección imprevisible. Por un lado, dice, su redacción del inciso primero incluye el término "promover". La misión del Estado es "promover el bien común", lo que indica que el Estado no tiene un papel pasivo. Además, la lectura conjunta de "promover" y "favorecer" le daría al Estado un carácter suficientemente dinámico. Con todo, las objeciones de Diez conservan algún sentido. En efecto, los verbos empleados por Guzmán en el inciso segundo son efectivamente 
blandos: asegurar, reconocer, amparar, garantizar, favorecer. Ellos implican un compromiso liviano, que tiende a facilitar un movimiento que le es externo. Naturalmente, la posición de Guzmán es perfectamente defendible -basta ser consciente de los riesgos de una intervención estatal excesiva para ver su plausibilidad-, pero es innegable que contiene una dirección convergente con cierto tipo de liberalismo (Actas, sesión n. 45, 13 de junio de 1974; ver también Moncada, 2006: 199). Por lo demás, es congruente con su comprensión del principio de subsidiariedad, que pone siempre el acento en las libertades individuales más que en las colectivas.

El principio de subsidiariedad es precisamente el concepto al que Guzmán se refiere constantemente en sus intervenciones. Cada vez que hay un desacuerdo respecto del orden económico-social, él intenta reconducirlo a su propia lectura de la subsidiariedad. Será nuevamente Sergio Diez el encargado de formular las reservas del caso. El argumento de Guzmán suele seguir el siguiente patrón: el Estado tiene el deber de suplir aquello que los particulares no logran hacer, o no realizan de modo satisfactorio; pero debe estar siempre dispuesto a retirarse apenas los particulares estén en condiciones de cumplir esos fines. Guzmán critica, por ejemplo, la idea de que es un deber primordial del Estado proveer de educación, pues eso le daría cierta prioridad respecto de los particulares. Según el, la participación estatal en el campo educacional es siempre subsidiaria y complementaria, porque hay dos derechos que la anteceden: el derecho de los padres a educar a sus hijos, y el "derecho de los particulares a abrir establecimientos de enseñanza y a ser sujetos activos de la tarea educacional" (Actas, sesión n. 143, 5 de agosto de 1975; ver San Francisco, 1992). Es importante notar que, a ojos de Guzmán, el principio de subsidiariedad sirve no solo para justificar el derecho de los padres a educar, sino que también el derecho de los particulares a emprender. Naturalmente, ambos derechos son correlativos, pero no necesariamente equivalentes, pues es el primero el que da sentido al segundo.

Por otro lado, Guzmán insiste con frecuencia en el carácter cualitativo del principio de subsidiariedad. Esto es, la subsidiariedad puede implicar que, en un determinado momento, el Estado se vea obligado a realizar la mayor parte de la labor educativa, e incluso la totalidad, pero es siempre para retirarse en el momento debido. Sergio Diez objeta esta visión del papel del Estado. Su crítica puede resumirse así: considerando las circunstancias concretas de la sociedad chilena, una definición de ese tipo es simplemente utópica. Para Diez, el problema educacional es "tan grave", que requiere de una acción permanente en todos los campos, por eso no hay "ninguna posibilidad real de que los particulares la enfrenten en profundidad y en extensión". Diez vuelve a la carga con su concepción de un Estado más activo: "el Estado no debe esperar lo que hagan los particulares para llenar los vacíos; sino que debe tomar la iniciativa", y dicha obligación "no es subsidiaria en los momentos que está viviendo el país". Diez considera que la Constitución política no puede ser una declaración de principios filosóficos, sino un cuerpo jurídico adaptado a las necesidades fácticas. Tampoco ve contradicción alguna entre afirmar el derecho preferente de los padres a educar al mismo tiempo que se entrega al Estado un papel activo (Jorge Ovalle formula argumentos muy semejantes, Actas, sesión n. 143, 5 de agosto de 1975). 
La discusión es muy reveladora, en cuanto permite ver una tensión entre dos modos de comprender la actividad del Estado. Para el líder gremialista, el Estado cumple siempre un papel supletorio, y por tanto debe estar dispuesto a retirarse; para Diez y Ovalle la profundidad y extensión de las necesidades sociales hacen indispensable un papel más activo porque, aun admitiendo la validez del principio de subsidiariedad, la Constitución debe regir un país que está lejos de satisfacer sus necesidades mediante la acción de los particulares. Guzmán repite, afirmando que las intervenciones de Diez y Ovalle le parecen "graves". Según él, "no es menoscabar la importancia de la función del Estado decir que es subsidiaria", sino que se trata simplemente de "fijarle un límite, un margen, un tope, para que no pretenda invadir en forma directa aquello que los particulares estén en condiciones de llevar a cabo por sí".

Esta orientación del principio de subsidiariedad se deja ver nuevamente con nitidez cuando la Comisión discute el problema de la salud pública: ¿la salud debe ser proveída por el Estado o por los particulares? Guzmán admite que el Estado debe preocuparse por estas materias, pero esa preocupación debe armonizarse con "el derecho de los ciudadanos a participar como particulares en la actividad determinada". Este último derecho, según Guzmán, "es preferente, incluso desde el punto de vista de la libertad, a la acción del Estado", que adquiere "un carácter subsidiario" (Actas, sesión n. 187). Es relevante notar aquí que el principio de subsidiariedad toma una orientación muy definida hacia el libre emprendimiento, que pasa a ser una de las articulaciones mayores de la sociedad. Algunas semanas más tarde, Guzmán refuerza su punto, e insiste en "el derecho a la iniciativa particular en materia de salud". Esto implica, en sus palabras, mucho más que libre elección de la atención médica, y no puede deducirse solamente de ese derecho. Más bien cabría, desde la perspectiva de Guzmán, consagrar de modo específico el derecho a la libre iniciativa, incluso antes del debate acerca del carácter o no subsidiario de dicha actividad. Guzmán afirma que es evidente que, en la medida en que la iniciativa particular crezca, el Estado va ir restringiendo su propia acción, pues le significa un gasto elevado. Por lo mismo, ni siquiera cree que valga la pena discutir demasiado respecto de la subsidiariedad en salud (Actas, sesión n. 192, 23 de marzo de 1976; ver también n. 205, 28 de abril de 1976, sobre seguridad social).

Esta argumentación nos permite ver aquello que pareciera ser el fondo de su pensamiento: Guzmán imagina un mundo donde los particulares van a cumplir progresivamente este tipo de tareas, y eso provocará el retiro mecánico del Estado. El problema consiste en lo que podríamos llamar la disposición moral de este Estado subsidiario que es constitutivamente insuficiente. En efecto, puede pensarse que hay cierto tipo de tareas que deben ser asumidas con una perspectiva u horizonte de tiempo más larga que aquella pensada por Guzmán: el Estado subsidiario que él propone tiende a ser mínimo porque está siempre en actitud fugaz. En muchos aspectos de la vida social, eso implica que su intervención será de menguada calidad, porque su compromiso es de baja intensidad. El papel del Estado se resume a suplir temporalmente, y luego desaparecer apenas sea posible. Pero ¿una sociedad de masas puede efectivamente resolver, por ejemplo, los problemas de salud, utilizando solo o principalmente los mecanismos de mercado? Guzmán no ve, o no quiere ver, los múltiples riesgos involucrados en la solución que 
propone. Por un lado, su idea supone un desarrollo económico muy elevado, que al menos acabe con algunos tipos de escasez. En el caso particular de la salud, ello es difícilmente pensable. El principio de subsidiariedad guzmaniano, en este sentido, tiene un cariz progresista: al final del camino, hay una sociedad pacificada que ha satisfecho todas sus necesidades por medio del mercado. Es, si se quiere, el principio de subsidiariedad llevado a un extremo cercano a la utopía libertaria.

Por otro lado, Guzmán piensa constantemente -cuando se refiere a la libre iniciativa de los particulares- en un mercado donde no existen las distorsiones, ni las asimetrías de información, ni las posiciones dominantes. Imagina, en definitiva, algo así como una competencia perfecta difícilmente compatible con la frágil realidad humana. Esta suposición es particularmente delicada en el caso de la salud, donde los bienes en juego son muy complejos y se prestan con mucha dificultad a las condiciones de la competencia perfecta. ${ }^{24}$ Naturalmente, Guzmán respondería nuestra objeción con el mismo argumento que repite en la Comisión: al ser cualitativo y no cuantitativo, el concepto de subsidiariedad permite toda la intervención estatal que sea necesaria. La dificultad estriba en que el razonamiento siempre supone un orden mejor, o perfecto, donde el Estado no actúa. Sin embargo, afirmaciones de ese tipo requerirían una argumentación histórica y filosófica que Guzmán nunca emprende: mal que mal, el Estado-nación es algo más que un mero remedio a las carencias contingentes de los particulares (ver Góngora, 1986). Incluso puede pensarse que surge justamente en respuesta a problemas que los particulares no pueden ni podrán resolver por sí solos. Pero hay más. La subsidiariedad de Guzmán está pensada siempre desde una antinomia entre el Estado y la sociedad civil (cuyo agente más relevante en su argumentación es el mercado). Esto tiene mucho sentido, pues es innegable que una acción estatal invasiva y concebida sin límites puede ahogar la actividad de las asociaciones intermedias. Con todo, en la medida en que el principio de subsidiariedad no busca proteger a los agentes económicos en cuanto económicos, sino a las agrupaciones intermedias de la sociedad en cuanto manifestaciones de vitalidad de la sociedad civil, la posición de Guzmán presenta dos problemas. Uno, que ya hemos vislumbrado, es su tendencia a identificar a los cuerpos intermedios con los agentes económicos, como si estos pudieran agotar aquello que la subsidiariedad busca preservar. El segundo problema, vinculado con el anterior, es que -al no percibir cuán compleja y multiforme es la sociedad civil- Guzmán no considera nunca que las amenazas a la vitalidad de las comunidades intermedias pueden venir no solo del Estado, sino también de la misma sociedad civil, que tiene diversos niveles de acción (cierta tendencia oligopólica del mercado, por ejemplo, puede poner en riesgo articulaciones muy relevantes de la sociedad civil). Dicho de otro modo, si el principio de subsidiariedad busca proteger la debida autonomía de los cuerpos intermedios, en vista al despliegue de lo humano que solo puede darse en su dimensión social, entonces es imprescindible no perder de vista que el Estado es solo una de las amenazas a ese tejido social, quizás la principal, pero en ningún caso la única. Estos deslizamientos le

24 En Mater et Magistra, Juan XXIII admite que en cuestiones de salud y educación la intervención estatal es consecuencia natural de las condiciones modernas (59-60). 
permiten a Guzmán hacer coincidir la subsidiariedad con el discurso más ortodoxo del liberalismo económico.

Es difícil pensar que Guzmán no tenía conciencia de las tensiones inherentes a su propuesta. Más bien cabría decir que tenía la convicción profunda de que su síntesis era aquello que políticamente podía resultar más funcional al objetivo de derrotar al comunismo. Por eso nos parece que sus ideas políticas no pueden, en ningún caso, ser sistematizadas sin referencia directa al contexto histórico que las explican: sus articulaciones carecen de sentido sin referencia al fenómeno de la Guerra Fría. Solo eso explica, por ejemplo, que nunca haya tomado en serio las críticas no marxistas dirigidas al capitalismo. ${ }^{25}$ En efecto, hay una larga reflexión relativa a los efectos del mercado respecto del orden cultural que no conduce necesariamente a posturas marxistas. De más está decir que la Doctrina social de la Iglesia es el primer ejemplo de este tipo de posiciones. Pero también podemos situar en este plano a la escuela ordoliberal (ver Audier, 2012), junto con algunas vertientes del pensamiento neoconservador (ver Bell, 1976 y Kristol, 1986). Sin embargo, Guzmán discutió poco y nada este tipo de críticas, prefiriendo apartarlas tan rápido como fuera posible: eran políticamente contradictorias con su proyecto. ${ }^{26}$

\section{CONCLUSIONES}

En todo caso, y más allá de las reservas, la interpretación del principio de subsidiariedad que ofrece Guzmán representa su esfuerzo más profundo por conciliar catolicismo y liberalismo económico: la convergencia solo puede ser pensada a partir de su singular lectura de este principio, teniendo siempre el anticomunismo como telón de fondo. En efecto, solo el anticomunismo puede proveer de (cierta) unidad al discurso de Guzmán. La coherencia intelectual no es su prioridad, porque tiende a definir sus ideas en función de objetivos políticos bien concretos, y eso explica su pragmatismo legendario (Huneeus, 2000: 342). Por eso, la indispensable crítica intelectual a Jaime Guzmán nunca puede perder de vista la dimensión eminentemente práctica de su pensamiento: Guzmán intenta conciliar distintas tradiciones para dar una respuesta políticamente viable a un determinado contexto histórico. Es por estos motivos que la lectura que Renato Cristi hace de Jaime Guzmán, aunque acertada por momentos, nos parece insuficiente: Cristi tiende a leer al líder gremialista como si se tratara de un profesor norteamericano de teoría política, y no un actor de primer orden de un escenario altamente movedizo y obligado a considerar en cada una de sus decisiones una multitud de variables. Al contrario de lo que supone Cristi, no hay en Guzmán una auténtica síntesis intelectual

25 Es importante señalar que hay un momento (1972) en el que Guzmán (¿por razones tácticas?) se permite criticar la estructura de la empresa capitalista, por excluir a los trabajadores de la gestión (Guzmán, 1991a: 295-296; retoma ideas de Rodríguez, 1972: 110-121; Valdivia, 2008: 374-375 ). Más tarde, en la comisión Ortúzar, Guzmán intentará reducir el papel de los sindicatos, y se mostrará hostil respecto del derecho de huelga (sesión n. 209, 11 de mayo de 1976).

26 Es curioso notar que, al enfrentar las críticas a los efectos perversos de la economía de mercado, Guzmán cambia sistemáticamente el plano de la discusión, llevando la discusión a un plano moral o ascético (Guzmán, 1991a: 297, 300 y 460). 
entre "neoliberalismo"y corporativismo, ni una adhesión demasiado profunda a las tesis de Hayek (ver por ejemplo Cristi y Ruiz-Tagle, 2014: 211 y 225). Guzmán simplemente toma elementos dispersos que le van permitiendo construir una síntesis cuyo carácter es político más que intelectual, y nunca realiza el esfuerzo de explicar filosóficamente cómo podrían combinarse todos esos elementos, por la sencilla razón de que sus motivos no son filosóficos. ${ }^{27}$

Como sea, la síntesis guzmaniana va a proveer al régimen de Pinochet un discurso innovador, y en ruptura con la tradición conservadora. Guzmán logra así la proeza de ganar la guerra de posiciones, y asumir una vanguardia histórica: mientras la izquierda quedaba con la incómoda tarea de defender un estatismo calificado de retardatario, el régimen encarnaba el cambio y el progreso (ver por ejemplo el texto de 1982, Guzmán, 1991a: 460 y Flisfisch, 1998: 65). Es quizás el único momento del siglo XX en que la derecha chilena pareció ir en el mismo sentido que la historia, y por eso Guzmán -más allá de las dudas que pueda merecer su elaboración intelectual- es con distancia el político de derecha más importante del siglo pasado.

Con todo, y si nos tomamos en serio la dimensión práctica del pensamiento guzmaniano, hay un elemento que naturalmente llama a interrogación. Si acaso es cierto que su síntesis solo cobra sentido en un contexto de Guerra Fría, donde el comunismo constituía una amenaza real para las democracias occidentales, entonces es innegable que el esquema pierde buena parte de su consistencia una vez disuelto ese contexto. No es imposible que este desfase esté en el origen de muchas de las tensiones que ha vivido Chile en los últimos años. El régimen instaurado durante la dictadura, y conservado en lo grueso durante la transición, fue un esfuerzo por eliminar del horizonte la amenaza marxista. Pero ¿qué sentido tiene su conservación luego del fin de esa amenaza? Quizás el principal desafío intelectual de la derecha chilena en el siglo XXI pasa por actualizar un discurso elaborado por Guzmán en un momento histórico singular y que, por lo mismo, ya no responde a las inquietudes actuales. Es, quizás, lo que habría hecho el mismo Guzmán, que nunca temió adaptar sus principios a una realidad en constante movimiento.

En ese sentido, parece innegable que hay algunas dimensiones cada vez menos plausibles en la síntesis de Guzmán. Por un lado, el fundador de la UDI tiende a pensar el capitalismo de un modo un poco estático, sin considerar las profundas transformaciones que este induce, ni el modo en el que puede horadar las bases culturales del mismo sistema. Naturalmente, todo orden engendra sus propias tensiones, y la economía de mercado no está exenta de ello, pero Guzmán no parece tenerlas a la vista. Un poco por lo mismo, la combinación de marcado liberalismo económico con conservadurismo moral se ha vuelto difícil de comprender (acerca de este problema, ver Michéa, 2009). Por otro lado, el liberalismo económico propugnado por Guzmán -fundamentado en un individualismo filosófico acentuado- deja un espacio muy menguado para la intervención

27 Resulta cuando menos curioso, por ejemplo, de que en su larga explicación de la subsidiariedad guzmaniana, Cristi no aluda nunca al anticomunismo de Guzmán, que opera como horizonte explicativo de su formulación del principio. La tesis de Cristi queda entonces desconectada de un principio que operó en una realidad política concreta, y que es difícilmente comprensible de modo puramente abstracto (Cristi, 2014: 209-229). 
estatal. Guzmán imagina un mundo en que el mercado permite pacificar la sociedad, pero sabemos que este genera conflictos y demandas que lo exceden. Por último, su noción de democracia protegida se ha vuelto sospechosa a ojos de una ciudadanía que quiere hacerse cargo de su destino colectivo, y que no se satisface completamente en el ejercicio de libertades económicas. En el fondo, Guzmán creía que los chilenos del siglo XXI podrían satisfacerse en el "apacible disfrute de la independencia privada" (Constant, 1997: 602). Es imposible no ver en las formulaciones de Guzmán la influencia de cierta filosofía de la historia, y quizás sea imprescindible tener ese hecho a la vista para evaluar adecuadamente su legado.

\section{REFERENCIAS}

Actas oficiales de la comisión de estudios para una nueva Constitución. En: http://www.ben.cl/lc/cpolitica/ actas_oficiales-r.

Arancibia, Patricia y Balart, Francisco. 2007. Sergio de Castro. El arquitecto del modelo económico chileno. Santiago: Biblioteca Americana.

Aron, Raymond. 1997. Introduction à la philosophie politique. Paris: Fallois.

Atria, Fernando. 2013. La constitución tramposa. Santiago: LOM.

Audier, Serge. 2012. Néolibéralisme(s): une archéologie intellectuelle. Paris : Grasset.

Barros, Robert. 2005. La junta militar. Pinochet y la Constitución de 1980. Santiago: Sudamericana.

Bell, Daniel. 1976. The Cultural Contradictions of Capitalism. New York: Basic Books.

Boetsch, Eduardo. 1998. Recordando con Alessandri. Santiago: Universidad Andrés Bello.

Constant, Benjamin. 1997. Écrits politiques. Paris : Gallimard.

Correa, Plinio. 1964. Entrevista en La Prensa (3 de noviembre).

1975. L'Église et l'État communiste: la coexistence imposible. Paris : Tradition, Famille Propriété. 2005. Revolución y contrarrevolución. Lima: Tradición y Acción.

Correa, Sofía. 2004. Con las riendas del poder. La derecha chilena en el siglo XX. Santiago: Sudamericana.

Cristi, Renato. 2011. El pensamiento político de Jaime Guzmán. Una biografía intelectual (2da edición). Santiago: LOM.

Cristi, Renato y Ruiz-Tagle, Pablo. 2014. El constitucionalismo del miedo, LOM, Santiago.

De Koninck, Charles. 1943. De la primauté du bien commun contre les personnalistes. Montréal: Université Laval.

Delsol, Chantal. 2013. L'État subsidiaire: ingérence et non ingérence de l'État. Le principe de subsidiarité aux fondements de l'histoire européenne. Paris: Karéline.

Descombes, Vincent. 2008. Philosophie du jugement politique. Paris: Seuil.

Evans, Michelle y Zimmermann, Augusto (eds.). 2014. Global Perspectives on Subsidiarity. Springer, Nueva York.

Fermandois, Joaquín. 2013. La revolución inconclusa: la izquierda chilena y el gobierno de la Unidad Popular. Santiago: CEP.

Flahault, François. 2005. Le paradoxe de Robinson. Capitalisme et société. Paris : Mille et une nuits.

Flisfisch, Ángel. 1998. “Tendencias ideológicas y decisiones políticas en el gobierno militar". En Análisis crítico del régimen militar, editado por Vial, Gonzalo (et al.). Santiago: Universidad Finis Terrae, 63-67.

Garáte, Manuel. 2012. La revolución capitalista de Chile. Santiago: Universidad Alberto Hurtado.

Garretón, Manuel Antonio. 2008. “La crisis de la democracia, el golpe militar y el proyecto contrarrevolucionario". En Análisis crítico del régimen militar, editado por Vial, Gonzalo (et al.). Santiago: Universidad Finis Terrae, 33-41.

Gazmuri, Cristián. 2013. ¿Quién era Jaime Guzmán? Santiago: RIL.

Ghersi, Mario. 2004. "El mito del neoliberalismo". Estudios Públicos 95: 293-313.

Góngora, Mario. 1986. Ensayo histórico sobre la noción de Estado en Chile. Santiago: Universitaria.

González Navarro, Luis Eduardo. 2012. "Fiducia y su cruzada contra la Democracia Cristiana. Chile 1962-1967". Divergencias 1: 21-33. 
Guzmán, Rosario. 1991. Mi hermano Jaime. Santiago: Ver.

Guzmán, Jaime. 1965. "El Capitalismo y los católicos de tercera posición”. Revista Fiducia 20: 4-5. 1981. “Participación: ¿cuál es su expresión básica?", La Segunda (3 de abril).

.1991a. "El miedo y otros escritos". Estudios Públicos 42: 251-570.

1991b. Su legado humano y politico. Santiago: Ercilla.

1992. Escritos personales. Santiago: Zig-Zag.

2003. Espiritualidad y fe en sus escritos. Santiago: Fundación Jaime Guzmán.

Huneeus, Carlos. 2000. El régimen de Pinochet. Santiago: Sudamericana.

Juan XXIII. 2001. Mater et Magistra. Santiago: Ediciones San Pablo.

Kristol, Irving. 1986. Reflections of a Neoconservative. New York: Basic Books.

León XIII. 2001. Rerum novarum. Santiago: Ediciones San Pablo.

Locke, John. 1997. Dos ensayos sobre el gobierno civil. Mardrid: Austral.

Michéa, Jean-Claude. 2009. Realm of Lesser Evil. Cambridge: Polity.

Moncada, Belén. 2006. Jaime Guzmán. Una democracia contrarrevolucionaria. Santiago: RIL. 2012. "Jaime Guzmán: una odisea político-racional". Estudios Públicos 125: 221-234.

Novak, Michael. 1984. El espíritu del capitalismo democrático. Buenoas Aires: Tres Tiempos.

Pío XI. 2001. Quadragesimo anno. Santiago: Ediciones San Pablo.

Rodríguez Grez, Pablo. 1972. Entre la democracia y la tiranía (sin indicación editorial).

Rojas, Gonzalo. 1991. “Tres proyectos para Jaime Guzmán”, Ercilla 2.906 (10 de abril). 1998. Chile escoge la libertad (vol. 1). Santiago: Zig-Zag.

Salazar, Manuel. 1994. Guzmán. Quién, cómo, por qué. Santiago: Bat.

San Francisco, Alejandro. 1992. "Jaime Guzmán y el principio de subsidiariedad educacional en la

Constitución de 1980". Revista chilena de derecho 19: 527-548.

Tocqueville, Alexis de. 2003. Lettres choisies. Souvenirs. Paris: Gallimard.

Tomás de Aquino. 1995. De regno Madrid: Tecnos. 2002. Suma Teológica. Madrid: Bac.

Valdivia, Verónica. 2003. El golpe después del golpe. Leigh vs. Pinochet. Santiago: LOM. 2008. Nacionales y gremialistas. Santiago: LOM.

Vial, Gonzalo. 2002. Pinochet. La biografía. Santiago: Aguilar. 2010. Augusto Pinochet y Jaime Guzmán. Santiago: Aifos.

VVAA. 1992. El ladrillo. Bases de la política económica del gobierno militar chileno. Santiago: CEP.

Daniel Mansuy es doctor en ciencia política y académico de la Universidad de los Andes (Santiago de Chile). E-mail: dmansuy@uandes.cl. 
